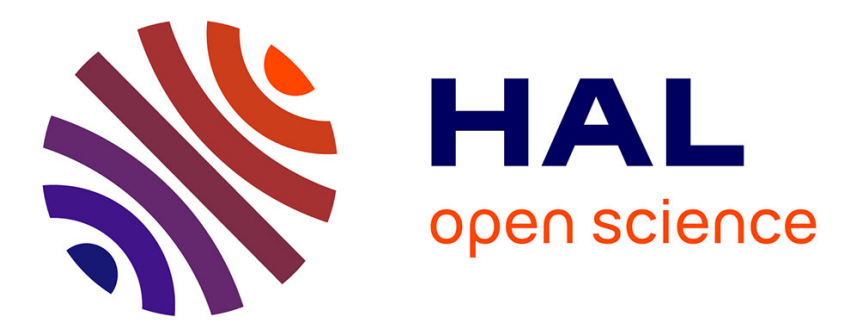

\title{
Expected satiation alone does not predict actual intake of desserts
}

Étienne Guillocheau, Olga Davidenko, Agnès Marsset-Baglieri, Nicolas Darcel, Claire C. Gaudichon, Daniel Tomé, Gilles Fromentin

\section{- To cite this version:}

Étienne Guillocheau, Olga Davidenko, Agnès Marsset-Baglieri, Nicolas Darcel, Claire C. Gaudichon, et al.. Expected satiation alone does not predict actual intake of desserts. Appetite, 2018, 123, pp.183-190. 10.1016/j.appet.2017.12.022 . hal-01783985

\section{HAL Id: hal-01783985 \\ https://hal.science/hal-01783985}

Submitted on 19 Sep 2019

HAL is a multi-disciplinary open access archive for the deposit and dissemination of scientific research documents, whether they are published or not. The documents may come from teaching and research institutions in France or abroad, or from public or private research centers.
L'archive ouverte pluridisciplinaire HAL, est destinée au dépôt et à la diffusion de documents scientifiques de niveau recherche, publiés ou non, émanant des établissements d'enseignement et de recherche français ou étrangers, des laboratoires publics ou privés. 
Étienne Guillocheau, Agnès Marsset-Baglieri, Nicolas Darcel, Claire Gaudichon, Daniel Tomé, et al.. Expected satiation is correlated with amplitude of intake but does not fit well with actual consumption of desserts. Appetite, Elsevier, 2018, 123, pp.468. 10.1016/j.appet.2017.11.081

\section{Expected satiation alone does not predict actual intake of desserts}

2

3 Etienne Guillocheau, Olga Davidenko, Agnès Marsset-Baglieri, Nicolas Darcel, Claire

4 Gaudichon, Daniel Tomé, Gilles Fromentin

5

6 (i) UMR Physiologie de la Nutrition et du Comportement Alimentaire, AgroParisTech, INRA, 7 Université Paris-Saclay, 75005, Paris, France

8

9 Corresponding author: Olga Davidenko, Physiologie de la Nutrition et du Comportement 10 Alimentaire, AgroParisTech, INRA, Université Paris-Saclay, 16 rue Claude Bernard, F1175005 Paris - E-mail: olga.davidenko@agroparistech.fr - Phone number +3314408 8637

12 
14 The degree to which consumers expect foods to satisfy hunger, referred to as expected 15 satiation, has been reported to predict food intake. Yet this relationship has not been established precisely, at a quantitative level. We sought to explore this relationship in detail

17 by determining whether expected satiation predicts the actual intake of semi-solid desserts. Two separate experiments were performed: the first used variations of a given food (eight apple purées), while the second involved a panel of different foods within a given category (eight desserts). Both experiments studied the consumption of two products assigned to

21 volunteers based on their individual liking and expected satiation ratings, given ad libitum at the end of a standardised meal. A linear model was used to find predictors of food intake and included expected satiation scores, palatability scores, BMI, age, sex, TFEQ-R, TFEQ-D, water consumption during the meal, reported frequency of eating desserts, and reported frequency of consuming tested products as explanatory variables. Expected satiation was a significant predictor of actual food intake in both experiments (apple purée: $F(1,97)=18.60$, $P<0.001$; desserts: $\mathrm{F}(1,106)=9.05, P<0.01)$, along with other parameters such as product palatability and the volunteers' age, sex and food restriction (variation explained by the model/expected satiation in the experiments: $57 \% / 23 \%$ and $36 \% / 17 \%$, respectively).

30 However, we found a significant gap between expected and actual consumption of desserts, 31 on group and on individual level. Our results confirm the importance of expected satiation as 32 a predictor of subsequent food intake, but highlight the need to study individual consumption 33 behaviour and preferences in order to fully understand the role of expected satiation.

35 KEYWORDS: Expected satiation; Food intake; Palatability. 


\section{INTRODUCTION}

37 It has been shown that most people are able to plan their meals in terms of portion size (Fay et 38 al., 2011; Hinton et al., 2013). Consumers can predict the degree to which foods are expected 39 to satisfy hunger when compared on a calorie-for-calorie basis, which is referred to as 40 expected satiation (Brunstrom \& Rogers, 2009). What is less studied today is whether 41 expected satiation is quantitatively related to actual food intake. It was reported that the 42 "perceived fillingness" score was the best predictor of actual food intake among military 43 personnel, since it could explain half of the variance associated with food intake (Pilgrim \& Kamen, 1963). In addition, expected satiation was found to be significantly correlated with the ideal portion size estimated by subjects (Brunstrom \& Rogers, 2009; Brunstrom \& Shakeshaft, 2009). Despite this, very little work has been done to connect expected satiation with real food intake: only one study by Wilkinson and colleagues (2012) suggested that among factors such as liking, appetite, food reward, body mass index (BMI) and food restriction and disinhibition scores, expected satiation might be a good predictor of food intake. However, this study was performed using only one food (pasta with sauce), and it would be difficult to generalise such findings to other commonly consumed foods. Expected satiation is also dependent on context. Indeed, expected satiation is more important when people are hungry than when sated (Brogden \& Almiron-Roig, 2010). Given this, desserts present several interests to study expected satiation: first, they constitute a particular food group which is well-understood by the general public yet offers a variability of sensory and nutritional characteristics; second, because desserts are consumed at the end of a meal when people are already starting to experience satiation, a situation that allows to control the nutritional state of volunteers in ecological conditions. Despite this, little work has yet been done on desserts (Forde, Almiron-Roig, \& Brunstrom, 2015). The objective of this study was 
therefore to expand our knowledge by studying the correlation between expected satiation and actual food intake using a range of desserts in the context of a meal.

This study had two objectives: (1) to confirm whether expected satiation could predict the actual food intake of desserts, and whether the accuracy of this predictor depends on the satiating power of the dessert or on its sensory characteristics; (2) to study the degree to which expected satiation can be considered as a measure of the amounts of food actually consumed, at both the group and individual levels.

\section{MATERIALS AND METHODS}

We present here the data resulting from two independent experiments which shared the same experimental design but featured different sets of products. The first study used eight apple purées only varying in texture ("apple purée" experiment), while the second used eight desserts commonly found on the French market ("dessert" experiment), which were more dissimilar. The objective of this second experiment was to verify whether the results obtained in the first experiment are generalisable to a larger group of foods. According to French law, the experimental protocols were approved by the French National Agency for Medicines and Health Products Safety (ANSM) and the Ethics Committee for Research Ile de France VII (“apple purée” experiment: \#2013-A00339-36; “dessert” experiment: \#2015-A00089-40). All participants received financial compensation for their participation. 
known to affect appetite. Pregnant or breast-feeding women, athletes in training, people with

86 a score $\geq 9$ on the restraint subscale (TFEQ-R) or $\geq 8$ on the disinhibition subscale (TFEQ-D)

87 of the Three-Factor Eating Questionnaire (Lesdema et al., 2012; Stunkard \& Messick, 1985)

88 were excluded from the study. Moreover, since both experiments involved foods usually

89 consumed as desserts, we only recruited volunteers who stated that they were generally used

90 to eating a dessert at the end of their meals. The power calculation estimated that 54 subjects

91 were necessary for each experiment to show a 33-g difference in food intake (1/3 of a standard portion) between the least and most satiating products with a power of 0.80 . In order to ensure spontaneous and natural behaviour during the sessions, the true purpose of the study was not disclosed to the participants; instead they were told that the aim was to adjust the recipes of the products (apple purées or desserts).

Fifty-four participants (14 M, $40 \mathrm{~F})$ were recruited for the "apple purée" experiment between January and June 2014, according to the recruitment criteria described above. Their mean 106

\section{Study products}

108 For each experiment, a set of eight products was designed so that products within the set 
110 among products), and (2) possibility to visually discriminate the products. The "apple purée"

111 experiment used eight apple purées obtained from one initial preparation (chunky apple purée

112 with no added sugar from Andros $\left.{ }^{\circledR}\right)$. The purees were adjusted in a way similar to that used

113 during a previous study by our team (Parizel et al., 2016) and varied in terms of particle size,

114 pulp content and the addition of apple fragments (see Table 1 for details), which resulted in 115 perceived visual and texture differences. The "dessert" study used a set consisting of eight 116 desserts selected from those commonly available in France and described during the same 117 previous study (Parizel et al., 2016). This assortment was based on a free sorting test carried 118 out by 32 untrained subjects (who were not the same as the participants in the present study) 119 that allowed us to choose the most dissimilar desserts among a set of 16 products. These 120 desserts included fruit purees, dairy products, custards and puddings; these differed with 121 respect to several sensory modalities (colour, texture, flavour) but had similar nutritional 122 contents (see Table 2 for details).

\section{Evaluation of expected satiation}

125 Expected satiation was evaluated using a variation of the method developed by (Wilkinson et 126 al., 2012). For each test food, 16 photographs were taken using a high-resolution digital 127 camera. The lighting conditions and viewing angles were identical for all photographs. The 128 test foods were arranged in identical transparent bowls (Duralex ${ }^{\circledR}, 135 \mathrm{~mm}$ diameter). The 129 portion size displayed on the photographs increased linearly in $25 \mathrm{kcal}$ steps, from $25 \mathrm{kcal}$ in 130 photograph 1 to $400 \mathrm{kcal}$ in photograph 16 . Photograph 4 corresponded to a standard (100 131 kcal) portion. Each photograph was identified by a random three-figure number, and the 16 132 photographs of each test food were gathered in a single picture displayed on a tablet 133 (Samsung ${ }^{\circledR}$ Galaxy Tab 2 10.1, Android 4.1.2). During the evaluation of expected satiation, 134 the participants were asked to look simultaneously at the 16 pictures, and then to "select the 
135 picture corresponding to the portion which they thought they needed to eat in order to feel full

136 at the end of lunch". In addition, the volunteers were given the bowl that had been used for

137 the pictures of each test food, thus enabling them to estimate the real quantity associated with 138 each picture.

\section{Experimental procedure}

141 Each experiment consisted in four sessions that took place at lunch time. The participants 142 were asked to attend at the same time for all sessions, between 11.30 a.m. and 1.30 p.m., with 143 a one-week minimum gap between each session. They were instructed to eat the same evening

144 meal the day before each test day and the same breakfast on each test day, and were asked to 145 consume no food or drinks, except for plain water, between their breakfast and the session. 146 During the sessions, the volunteers were served lunch in a quiet room free of any food 147 references or other sources of distraction. Each participant was seated alone at a table, and 148 visual contact between the volunteers was not possible. At the start of each session, the 149 participants were first asked to indicate, on a 100-mm unmarked visual analogue scale (VAS), 150 how they were feeling at the time they completed the following questions: How hungry do 151 you feel now? (VAS anchors: not hungry at all-extremely hungry); How full do you feel 152 now? (not full at all-extremely full); How strong is your desire to eat now? (very weak-very 153 strong); How much food do you think you could eat now? (nothing at all-a large amount); 154 How thirsty do you feel now? (not thirsty at all-extremely thirsty) (using a French translation 155 of the questions recommended by Blundell et al., 2010).

\section{Session 1: Expected satiation}

157 After answering the appetite questionnaire, the participants were first of all served a main 158 course composed of pasta with tomato sauce (Penne Tomate Basilic, Panzani ${ }^{\circledR}$ ) and $500 \mathrm{~mL}$ water. The pasta dish was served ad libitum and the participants were instructed to eat as 
160 much as they wanted. The amounts of pasta and water consumed were then weighed and

161 recorded with $0.1 \mathrm{~g}$ accuracy. Once the participants had eaten the pasta to fullness, they were 162 asked to score its palatability using a 100-mm VAS (question: "How much do you like this 163 dish?", anchors: not at all-very much indeed). Next, the participants evaluated the expected 164 satiation associated with the set of products used during the experiment to which they 165 belonged (apple purées or desserts). The products were presented using a sequential monadic 166 procedure, following a Williams Latin square design (Williams, 1949). First, a 25g sample of 167 the test food was served to the subjects and they were instructed to taste it and score its 168 palatability using a 100-mm VAS similar to that used for the pasta. Next, the subjects scored 169 the expected satiation of the product, as described previously.

\section{Product assignment}

171 After the session on expected satiation, two foods from the set were assigned individually to 172 each volunteer as a function of their individual expected satiation scores: the product for 173 which the volunteer selected the smallest portion (referred to as "the most satiating product" 174 below), and the product for which the volunteer selected the biggest portion (referred to as 175 "the least satiating product" below). This was done in order to study whether the subjects 176 behave the same when they consume products providing different levels of expected satiety.

177 Since it has been shown that palatability may impact satiation (Bobroff \& Kissileff, 1986), 178 pairs of products were selected in such a way as to minimise differences in palatability, 179 whenever possible.

\section{Sessions 2, 3 and 4: Food intake}

181 During three subsequent sessions, the actual food intake of the two individually assigned 182 products was measured. A single product was provided during each session. Two sessions 183 featured the least satiating product in order to evaluate the stability of each participant's 184 behaviour. The order of sessions was randomised. In the same way as for the expected 
satiation session, the volunteers were first asked to complete the appetite questionnaire. Next,

186 they were served the same amount of pasta as they had eaten during the expected satiation 187 session, and were told to clean the plate (all participants complied with the instructions during 188 all sessions). $500 \mathrm{~mL}$ water was also available. After cleaning their plates, the volunteers

189 scored the palatability of the pasta dish, as described above. They were then given a bowl 190 containing $400 \mathrm{kcal}$ of one of the individually assigned products as their dessert, and were

191 instructed to eat it until they felt full. Afterwards, they were asked to score the palatability of 192 the product using the same method as during the expected satiation session. Any remaining 193 amounts of dessert and water (for the "dessert" experiment) were weighed and recorded with 194 an accuracy of $0.1-\mathrm{g}$. At the end of the last food intake session, the subjects were asked to 195 state their frequency of consumption of the study desserts. For the "apple purée" experiment, 196 they were asked to answer the question: "How often do you eat apple purée?" They had to 197 choose between four answers: "At least once a week", "At least once a month", "At least once 198 a year", "Less than once a year". For the "dessert" experiment, the identities of the 199 individually assigned products were disclosed to the participants and they were asked the 200 same question for each dessert separately.

\section{Data analysis}

203 The effect of the product on palatability scores collected during the expected satiation session 204 was analysed using one-way ANOVA. The effect of product and palatability on expected 205 satiation scores (expressed as energy (kcal) and volume (in L)) were analysed using 206 ANCOVA. Bonferroni post hoc corrections were applied for multiple comparisons.

207 For each session, the appetite score of each participant was calculated as follows:

208 Appetite score $=\frac{(\text { Hunger }+ \text { Prospective consumption }+ \text { Desire to eat })+(100-\text { Fullness })}{4}$ 
209 Before further analysis, the stability of food behaviour was assessed using the data acquired

210 during food intake sessions involving the least satiating product. Linear mixed models were

211 used to analyse appetite scores, palatability scores and the amount of product consumed (as

212 energy or as volume). The session, BMI, age, sex, TFEQ-R and TFEQ-D were used as fixed

213 effects and the participant as a random effect in order to adjust for repeated measures.

214 The stability of appetite scores, palatability ratings, and amount of water consumed during the 215 food intake sessions ("dessert" experiment only) for products during each session was 216 assessed using linear mixed models with the session, BMI, age, sex, TFEQ-R and TFEQ-D as 217 fixed effects and the participant as a random effect. Tukey post hoc tests were used to 218 estimate the means.

219 A linear model was constructed in order to assess predictors of food intake (as energy or as 220 volume). This model included expected satiation scores (as energy or as volume), palatability 221 scores, mean amount of water consumed during the food intake sessions (for the "dessert" experiment only), BMI, age, sex, TFEQ-R, TFEQ-D, reported frequency of eating a dessert at 223 the end of a meal, and reported frequency of consuming the test foods as explanatory 224 variables.

225 Because expected satiation and actual food intake data were not collected using the same 226 method, these parameters could not be compared using a single procedure. Four linear mixed 227 models were therefore used to compare (1) expected satiation vs. actual food intake 228 (separately for two individually selected products), and (2) actual food intake of two 229 individually selected products (separately for expected satiation session and food intake 230 sessions). All models included BMI, age, sex, TFEQ-R, TFEQ-D, mean amount of water 231 consumed during the food intake sessions (for the "dessert" experiment only), reported 232 frequency of eating a dessert at the end of a meal and reported frequency consumption of test 233 foods as fixed factors and the participant as a random factor. 
234 Individual intake data were studied by computing the difference between actual food intake 235 and expected satiation relative to the two individually assigned products for each subject. We 236 considered there was a match between expected satiation and actual food intake if this 237 difference was less than $1 / 3$ of a portion $(33 \mathrm{~g})$.

238 All statistical computations were carried out using R 3.2.1. for Windows (http://www.cran.r239 project.org/), using the "car" and "Ime" packages, and type II tests. P-values $<0.05$ were 240 considered to be statistically significant. All data are presented as mean \pm SEM.

\section{RESULTS}

\section{EXPERIMENT 1: APPLE PURÉES}

\section{Stability of food behaviour and appetite sensations}

245 For food intake sessions involving the least satiating apple purée, there was no significant 246 effect of the session on appetite status $\left(\chi^{2}(1)=0.003\right.$, NS), palatability scores $\left(\chi^{2}(1)=0.62\right.$, 247 NS) and the amount of apple purée actually consumed (energy content and volume: $\chi^{2}(1)=$ 2480.14 , NS). Therefore, the mean values of the two sessions were used for subsequent analyses. 249 No significant effect of the session was seen regarding the appetite status of volunteers $\left(\chi^{2}(1)\right.$ $250=5.62, \mathrm{NS})$ during the four study sessions.

254 We found a significant product effect on palatability scores $(\mathrm{F}(7,408)=3.22, P<0.01)$, during 255 the expected satiation session (see Table 1). There was no significant effect of product on 256 expected satiation scores, expressed as energy $(F(7,407)=0.72, \mathrm{NS})$ or as volume $(\mathrm{F}(7,407)=$ 2570.73 , NS), but the palatability effect on expected satiation was significant (energy and 258 volume: $\mathrm{F}(1,407)=117.9, P<0.001)$. 
Palatability scores for individually assigned apple purées

261 The most satiating apple purée was rated as being significantly less palatable than the least satiating apple purée during the expected satiation session $(P<0.001$, see Figure 1A). During 263

\section{Expected satiation and food intake}

271 We found a significant difference in expected satiation ratings between the most satiating and 272 least satiating apple purées (energy: $\chi^{2}(1)=51.46, P<0.001$, see Figure $1 \mathrm{~B}$; volume: $\chi^{2}(1)=$ 273 274 $52.19, P<0.001$ see Figure 1C). This difference remained throughout the food intake sessions 280

\section{Predictors of food intake}

282 The linear model revealed that actual food intake (as energy) was predicted by expected 283 satiation $(\mathrm{F}(1,97)=18.60, P<0.001)$, sex $(\mathrm{F}(1,97)=17.66, P<0.001)$, TFEQ-R $(\mathrm{F}(1,97)=$ 
20.95, $P<0.001)$, age $(\mathrm{F}(1,97)=5.50, P<0.05)$ and the palatability score given during the

285 food intake session $(\mathrm{F}(1,97)=6.64, P<0.05)$. The model accounted for $57 \%$ of the variance associated with food intake $\left(R^{2}=0.57\right)$. Expected satiation was the first predictor in terms of explained variance $(23 \%)$. After adjustment for the reported frequency of eating a dessert at the end of a meal, and the reported frequency of consuming apple purées, these parameters 289 remained significant predictors of food intake. The adjusted model accounted for $58 \%$ of the 290 variance in food intake $\left(R^{2}=0.58\right)$. Comparable results were obtained when expressing food 291 intake as volume. Expected satiation, sex, TFEQ-R, age and palatability scores at the food 292 intake session remained good predictors of actual food intake, even when adjusting for 293 experience parameters. Likewise, the adjusted model accounted for more than the half of the 294 variance associated with food intake when expressed as volume $\left(R^{2}=0.58\right)$.

\section{Consistency between food intake and expected satiation at an individual level}

297 Individual food intake was plotted against expected satiation (as energy) for the most and 298 least satiating apple purées (see Figure 3). The actual food intake of the most satiating apple 299 purée was higher than the expected satiation in all participants except one. However, some 300 participants consumed less of the least satiating apple purée than expected, and the differences 301 between expected and actual consumption were within a broader range for this product. After 302 matching individual values, we found that only five subjects consumed within $1 / 3$ of a portion $303(+/-33 \mathrm{~g}$ or $+/-18.7 \mathrm{kcal})$ of the expected satiation of both products. Four more subjects were 304 within the limits for the most satiating puree only and 11 for the least satiating puree only. 305

306 EXPERIMENT 2: DESSERTS

307 Stability of food behaviour and appetite sensations 
308 There was no significant effect of the session on appetite status $\left(\chi^{2}(1)=0.40\right.$, NS), palatability

309 scores $\left(\chi^{2}(1)=0.09, \mathrm{NS}\right)$ and the amount of the least satiating dessert consumed during two 310 food intake sessions (energy: $\chi^{2}(1)=0.23$, NS; volume: $\chi^{2}(1)=0.32$ ). Therefore, as for the

311 "apple purée" experiment, the mean values of the two sessions were used for subsequent 312 analyses. No significant effect of session was found on the appetite status of volunteers $\left(\chi^{2}(1)\right.$ $313=5.54, \mathrm{NS}$ ) during the four study sessions. No significant effect of session was found on the 314 amount of water consumed during the food intake sessions $\left(\chi^{2}(2)=1.1092, \mathrm{NS}\right)$.

\section{Expected satiation session: palatability and expected satiation for the entire dessert set}

317 We found a product effect on the palatability scores $(\mathrm{F}(7,447)=2.82, P<0.01$, see Table 2$)$

318 collected during the expected satiation session. There was no significant effect of product $319(\mathrm{~F}(7,447)=0.48$, NS) on expected satiation scores when expressed as energy. However, we observed an significant effect of product $(\mathrm{F}(7,447)=4.29, P<0.001)$ when expected satiation $\mathrm{F}(1,447)=98.22, P<0.001)$

\section{Palatability scores of individually assigned desserts}

326 The most satiating dessert was rated as being significantly less palatable than the least 327 satiating dessert during the expected satiation session $(P<0.001$, see Figure $2 \mathrm{~A})$. The most 328 satiating dessert was consistently associated with a lower palatability score during the food 329 intake sessions when compared to the least satiating dessert $(P<0.001)$. No significant 330 difference in palatability scores was found between the expected satiation session and food 331 intake sessions $(P=0.99$ and $P=0.13$ for the least and most satiating desserts, respectively). 
332 The mean palatability for each dessert was therefore determined and used for subsequent

333 calculations.

334

\section{Expected satiation and actual food intake}

336 As expected, the expected satiation scores assigned to the most and least satiating desserts 337 were significantly different (energy: $\chi^{2}(1)=115.24, P<0.001$, see Figure 2B; volume: $\chi^{2}(1)=$ $33890.97, P<0.001$, see Figure 2C). However, actual intakes did not differ between these two 339 desserts (energy: $\chi^{2}(1)=0.32$, NS; volume: $\chi^{2}(1)=1.15$, NS). Participants consumed 340 significantly more of the most satiating dessert than expected (energy: $\chi^{2}(1)=24.60, P$ $341<0.001$; volume: $\left.\chi^{2}(1)=23.16, P<0.001\right)$, while the reverse applied for the least satiating 342 dessert (energy: $\chi^{2}(1)=14.03, P<0.001$; volume: $\chi^{2}(1)=15.88, P<0.001$ ). 343

344 Predictors of food intake

345 The linear model revealed that actual food intake (expressed as energy) was predicted by 346 palatability $(\mathrm{F}(1,105)=22.56, P<0.001)$, expected satiation $(\mathrm{F}(1,105)=7.92, P<0.01)$ and 347 TFEQ-R $(\mathrm{F}(1,105)=4.99, P<0.05)$. The model accounted for $36 \%$ of the variance associated 348 with food intake $\left(R^{2}=0.36\right)$. Expected satiation was the first predictor $(17 \%$ expected 349 variance) and palatability explained $11 \%$ of the total variance. Expected satiation and 350 palatability, but not the TFEQ-R, remained significant after adjustment for the reported 351 frequency of eating a dessert at the end of a meal, and the reported frequency of consuming 352 both contrasting desserts. The adjusted model accounted for $40 \%$ of the variance associated 353 with food intake $\left(R^{2}=0.40\right)$. When actual food intake was expressed as volume, palatability 354 and expected satiation remained significant predictors of food intake before $(\mathrm{F}(1,105)=$ $35516.51, P<0.001$ and $\mathrm{F}(1,105)=4.38, P<0.05$, respectively) and after adjustment $(\mathrm{F}(1,105)=$ 
consumed during the session became a significant predictor as well (before adjustment:

$358 \mathrm{~F}(1,105)=7.59, P<0.01$; after adjustment: $\mathrm{F}(1,105)=8.15, P<0.01)$. The adjusted model

accounted for more than a third of the variance associated with food intake $\left(R^{2}=0.35\right)$.

360

\section{1}

362

363

364

\section{Consistency between actual food intake and expected satiation at an individual level}

Individual differences between actual food intake and expected satiation (as energy) regarding the most and least satiating apple purées are plotted on Figure 4. Most volunteers $(75 \%)$ consumed more of the most satiating dessert than expected. We observed more mixed results with the least satiating dessert. Only five subjects consumed within $1 / 3$ of a portion $(+/-33 \mathrm{~g}$ or $+/-33.4 \mathrm{kcal}$ ) from the expected portions of both desserts. Twenty-four more were within the range for one of the products (nine for the least satiating and 15 for the most satiating, respectively).

\section{DISCUSSION}

Our experiments studied the relationship between expected satiation and the actual intake of common semi-liquid desserts. We used a set of versions of a single food (the "apple purée" experiment, products varying in texture only) and a set of different foods within a given category (the "dessert" experiment, products varying in different characteristics) in order to generalize the results of the first experiment to a wider food category. Furthermore, the use of individually assigned products allowed us to study the relationship between expected satiation and actual intake using a within-subject design, and to test the robustness of the relationship between these parameters for different levels of expected satiation. During both experiments, we found that expected satiation was a significant predictor of the actual intake of selected products. Nevertheless, the quantities actually consumed were close (within $33 \mathrm{~g}$ ) to the expected portions in only a small minority of subjects (9\%), while actual intakes were stable 
382 across the sessions. We must therefore conclude that expected satiation could not be

383 considered as an alternative measure of food intake in the case of spoonable desserts, and

384 other factors should be taken into account.

385 Our study showed that expected satiation is a significant predictor of the actual intake of 386 desserts, alongside palatability and other factors such as age, sex or TFEQ-R scores. Our 387 findings were partly in contradiction with previous results which had shown that expected 388 satiation was the only significant predictor of intake (Wilkinson et al,, 2012). Such a 389 difference in the results might have been caused by our choice to work with desserts, products 390 that are more likely to be consumed for their hedonic value than the pasta with sauce used in 391 Wilkinson's study. The variance associated with palatability was therefore higher in our 392 experiment.

393 While expected satiation performed quite well as a predictor of actual intake within the linear 394 model, the results were more nuanced when expected satiation scores and actual intakes were 395 compared quantitatively. With the exception of the least satiating apple puree, a significant 396 difference was observed between mean actual intake and mean expected satiation, in line with 397 the findings of a previous study (P S Hogenkamp, Mars, Stafleu, \& de Graaf, 2012). In order 398 to determine the proportion of participants who could be considered as "consistent", we fixed 399 a threshold of congruence between actual intakes and expected satiation. Although this 400 threshold was chosen to be relatively permissive (1/3 of a standard portion), only ten out of 401111 participants $(9 \%)$ fell within this threshold for both the most and the least satiating 402 products, and a further 39 (35\%) fell within this threshold for only one of the two products. 403 The difference between expected and actual intake could be explained by a significant change 404 in mean palatability scores between sessions for the most satiating apple purée (35 and 52 for 405 the expected satiation session and food intake session, respectively) (Bobroff \& Kissileff, 406 1986), because palatability was identified as a predictor of actual intake. But although 
407 palatability remained constant in the "dessert" experiment, we observed even less consistency

408 between expected and actual intakes during the second study, thus showing that factors other than palatability might be involved. One of such factors might be the nature of the products used. Indeed, purées and desserts eaten with a spoon are usually consumed in individual prepackaged portions of comparable size. While the intakes recorded ad libitum were likely to reflect a real willingness to eat, they still might have been influenced by previous experiences with pre-packaged foods. This could explain why we did not observe difference in actual intake between the most and the least satiating product in the "dessert" study. Previous experience with such foods might have driven the subjects to consume a portion close to the habitual portion, disregarding the difference in palatability (high enough in case of desserts). Besides, it is possible that during the "expected satiation" session, the task of judging eight products simultaneously led to a more precise categorisation during the expected satiation session and caused more differentiation in palatability and expected satiation by a process comparable to a hedonic contrast effect where "good things (here, better liked products) make less good things even worse" (Hayes, DePasquale, \& Moser, 2011; Parizel et al., 2015; Zellner, Allen, Henley, \& Parker, 2006). Compared to this, the food intake sessions involved a more natural situation of consuming one dessert and partly abolished satiation and palatability differences. Finally, the amount of water intake displayed a significant influence on the volume of desserts consumed. Still, since the actual consumption was not systematically lower than anticipated, water did not suppress the intake, and besides, water intake was not a predictor of caloric intake.

Beyond its influence on actual intake, in both experiments palatability also appeared to be correlated with expected satiation itself, although the study design does not allow to draw a causality relationship. By contrast, the product effect appeared to be a less important determinant of expected satiation, particularly in the "apple purée" experiment. This was 
432 contrary to what had been expected, because the apple purées we used varied in texture and 433 previous studies had shown that texture influences expected satiation (Pleunie S Hogenkamp,

434 Stafleu, Mars, Brunstrom, \& de Graaf, 2011; McCrickerd, Chambers, Brunstrom, \& 435 Yeomans, 2012). However, previous findings were based on much more diverse sets of 436 products, ranging from solid to liquid, while the apple purées in our experiment were all semi437 solid and varied in density and the amount of chunks rather in terms of their food form. The 438 same applied to the set of products used in the "dessert" experiment. However, in the second 439 experiment, differences in expected satiation could be explained by the product factor when it was expressed in volume rather than in calories. This might signal an adjustment of consumption for energy rather than for volume, as the product set in the "dessert" experiment was more variable in caloric density $(\mathrm{SD}=0.094)$ than the set used for the "apple purée" experiment $(\mathrm{SD}=0.005)$. How energy density can be detected at the stage of expected satiation still needs to be studied.

Our experiments used foods that are usually consumed as desserts and they were served at the end of a lunch. This design served two purposes: first, it was more ecological because the desserts are chosen and consumed at the end of the meal, and second, the standardised main course allowed us to control the appetite status of the volunteers, because it has been shown that appetite status impacts expected satiation (Brogden \& Almiron-Roig, 2010). This design differed crucially from that of previous studies involving a variety of test foods from different categories. For instance, the study by (Brunstrom, Shakeshaft, \& ScottSamuel, 2008) included main courses (pizza, boiled potatoes), but also snack foods (crackers, potato crisps) and other types of foods (fresh banana). Our design explains the overall stability of expected satiation among test foods, as well as that of liking scores and actual intakes. However, our experiments only used semi-solid foods that could be eaten with a spoon. The 
456 outcomes might have been different if we had included solid desserts such as pies or fruit 457 pieces, or liquids such as milkshakes.

\section{CONCLUSIONS}

460 Our results may generate conflicting views regarding the importance of expected satiation to 461 food intake in humans. On the one hand, our study confirmed that expected satiation is a 462 predictor of actual intake, which is consistent with previous studies. However, we also 463 showed that other parameters, and especially palatability, were also predictors of intake. The 464 importance of expected satiation could therefore be questioned if it were to be considered as a 465 means of controlling food intake, especially in case of highly palatable foods. Reasoning at an 466 individual level, taking into account personal preferences, is necessary if the objective is to 467 limit the consumption of highly palatable foods such as desserts, for example in order to 468 control weight gain. Further research is now needed to fully understand the role of expected 469 satiation as it relates to food intake, in different individuals and food groups.

471 Funding acknowledgement. This research did not receive any specific grant from funding 472 agencies in the public, commercial, or not-for-profit sectors. 


\section{REFERENCES}

475

476

477

478

479

480

481

482

483

484

485

486

487

488

489

490

491

492

493

494

495

496

497

498

499

500

501

502

503

504

505

506

507

508

509

510

511

512

513

514

515

516

Blundell, J., De Graaf, C., Hulshof, T., Jebb, S., Livingstone, B., Lluch, A., ... Westerterp, M. (2010). Appetite control: methodological aspects of the evaluation of foods. Obesity Reviews, 11(3), 251 $\square 270$. https://doi.org/10.1111/j.1467-789X.2010.00714.X

Bobroff, E. M., \& Kissileff, H. R. (1986). Effects of changes in palatability on food intake and the cumulative food intake curve in man. Appetite, $7(1), 85 \square 96$.

Brogden, N., \& Almiron-Roig, E. (2010). Food liking, familiarity and expected satiation selectively influence portion size estimation of snacks and caloric beverages in men. Appetite, 55(3), 551 $\square$ 5. https://doi.org/10.1016/j.appet.2010.09.003

Brunstrom, J. M., \& Rogers, P. J. (2009). How many calories are on our plate? Expected fullness, not liking, determines meal-size selection. Obesity (Silver Spring, Md.), 17(10), 1884 $\square 90$. https://doi.org/10.1038/oby.2009.201

Brunstrom, J. M., \& Shakeshaft, N. G. (2009). Measuring affective (liking) and nonaffective (expected satiety) determinants of portion size and food reward. Appetite, 52(1), $108 \square$ 14. https://doi.org/10.1016/j.appet.2008.09.002

Brunstrom, J. M., Shakeshaft, N. G., \& Alexander, E. (2010). Familiarity changes

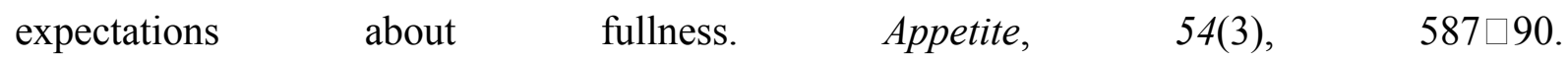
https://doi.org/10.1016/j.appet.2010.01.015

Brunstrom, J. M., Shakeshaft, N. G., \& Scott-Samuel, N. E. (2008). Measuring « expected satiety $»$ in a range of common foods using a method of constant stimuli. Appetite, 51(3), 604 $\square$ 14. https://doi.org/10.1016/j.appet.2008.04.017

Fay, S. H., Ferriday, D., Hinton, E. C., Shakeshaft, N. G., Rogers, P. J., \& Brunstrom, J. M. (2011). What determines real-world meal size? Evidence for pre-meal planning. Appetite, 56(2), 284 $\square$ 9. https://doi.org/10.1016/j.appet.2011.01.006

Forde, C. G., Almiron-Roig, E., \& Brunstrom, J. M. (2015). Expected Satiety: Application to Weight Management and Understanding Energy Selection in Humans. Current Obesity Reports, 4(1), 131 $\square$ 140. https://doi.org/10.1007/s13679-015-0144-0

Hayes, J. E., DePasquale, D. A., \& Moser, S. E. (2011). Asymmetric dominance as a potential source of bias in hedonic testing. Food Quality and Preference, 22(6), 559 $\square 566$. https://doi.org/10.1016/j.foodqual.2011.03.006

Hinton, E. C., Brunstrom, J. M., Fay, S. H., Wilkinson, L. L., Ferriday, D., Rogers, P. J., \& de Wijk, R. (2013). Using photography in « The Restaurant of the Future ». A useful way to assess portion selection and plate cleaning? Appetite, 63, $31 \square 5$. https://doi.org/10.1016/j.appet.2012.12.008

Hogenkamp, P. S., Mars, M., Stafleu, A., \& de Graaf, C. (2012). Repeated consumption of a large volume of liquid and semi-solid foods increases ad libitum intake, but does not change expected satiety. Appetite, 59(2), 419 $\square 24$. https://doi.org/10.1016/j.appet.2012.06.008

Hogenkamp, P. S., Stafleu, A., Mars, M., Brunstrom, J. M., \& de Graaf, C. (2011). Texture, not flavor, determines expected satiation of dairy products. Appetite, 57(3), $635 \square 41$. https://doi.org/10.1016/j.appet.2011.08.008

Irvine, M. A., Brunstrom, J. M., Gee, P., \& Rogers, P. J. (2013). Increased familiarity with eating a food to fullness underlies increased expected satiety. Appetite, 61(1), $13 \square 8$. https://doi.org/10.1016/j.appet.2012.10.011 
Lesdéma, A., Fromentin, G., Daudin, J.-J., Arlotti, A., Vinoy, S., Tomé, D., \& MarssetBaglieri, A. (2012). Characterization of the Three-Factor Eating Questionnaire scores of a young French cohort. Appetite, 59(2), 385 $\square 90$. https://doi.org/10.1016/j.appet.2012.05.027

McCrickerd, K., Chambers, L., Brunstrom, J. M., \& Yeomans, M. R. (2012). Subtle changes in the flavour and texture of a drink enhance expectations of satiety. Flavour, 1(1), 20. https://doi.org/10.1186/2044-7248-1-20

Parizel, O., Sulmont-Rossé, C., Fromentin, G., Delarue, J., Labouré, H., Benamouzig, R., $\&$ Marsset-Baglieri, A. (2015). The structure of a food product assortment modulates the effect of providing choice on food intake. Appetite. https://doi.org/10.1016/j.appet.2015.11.018

Pilgrim, F. J., \& Kamen, J. M. (1963). Predictors of Human Food Consumption. Science (New York, N.Y.), 139(3554), 501 $\square 2$. https://doi.org/10.1126/science.139.3554.501

Stunkard, A. J., \& Messick, S. (1985). The three-factor eating questionnaire to measure dietary restraint, disinhibition and hunger. Journal of Psychosomatic Research, 29(1), $71 \square 83$. https://doi.org/10.1016/0022-3999(85)90010-8

Wilkinson, L. L., Hinton, E. C., Fay, S. H., Ferriday, D., Rogers, P. J., \& Brunstrom, J. M. (2012). Computer-based assessments of expected satiety predict behavioural measures of portion-size selection and food intake. Appetite, $\quad 59(3), \quad 933 \square 8$. https://doi.org/10.1016/j.appet.2012.09.007

Williams, E. (1949). Experimental Designs Balanced for the Estimation of Residual Effects of Treatments. Australian Journal of Chemistry, 2(2), 149. https://doi.org/10.1071/CH9490149

Zellner, D. A., Allen, D., Henley, M., \& Parker, S. (2006). Hedonic contrast and condensation: Good stimuli make mediocre stimuli less good and less different. Psychonomic Bulletin \& Review, 13(2), 235 $\square 239$. https://doi.org/10.3758/BF03193836 
$\vec{\omega} \vec{\omega} \vec{\omega} \vec{\omega} \vec{\omega} \vec{\omega} \vec{\omega} \vec{\omega} \vec{\omega} \vec{\omega} \vec{\omega} \vec{\omega} \vec{\omega} \vec{\omega} \vec{\omega} \vec{\omega} \vec{\omega} \vec{\omega} \vec{\omega} \vec{\omega} \vec{\omega} \vec{\omega} \vec{\omega} \vec{\omega} \vec{\omega} \vec{\omega} \vec{\omega} \vec{\omega} \vec{\omega} \vec{\omega} \vec{\omega} \vec{\omega} \vec{\omega} \vec{\omega} \vec{\omega} \vec{\omega} \vec{\omega} \vec{\omega} \vec{\omega} \vec{\omega} \vec{\omega} \vec{\omega} \vec{\omega} \vec{\omega}$

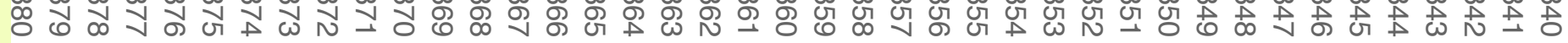

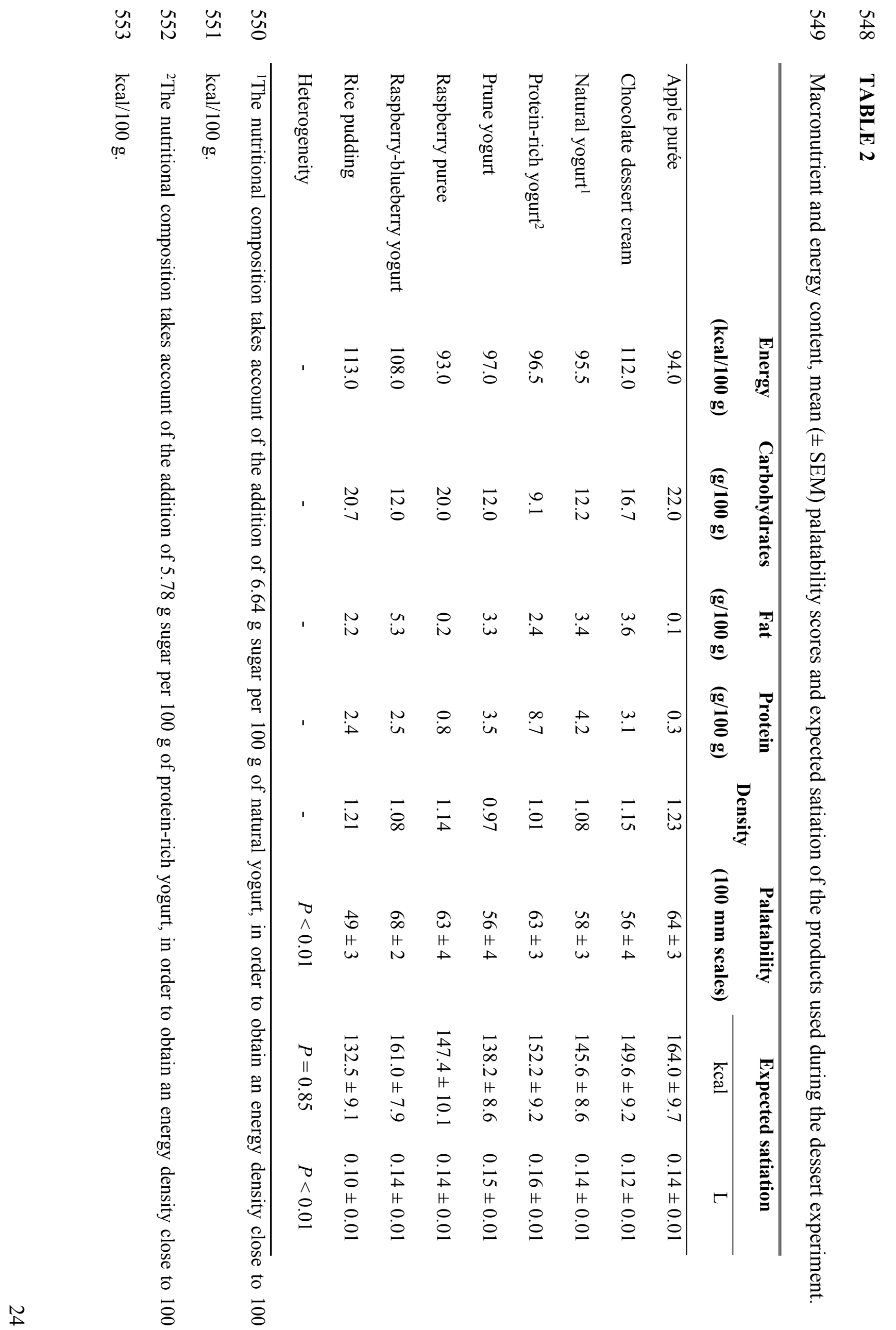




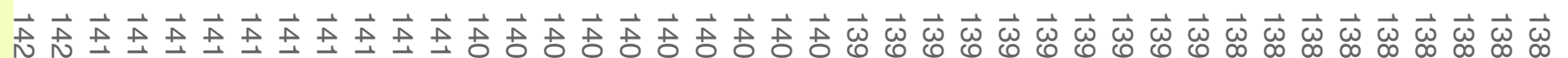

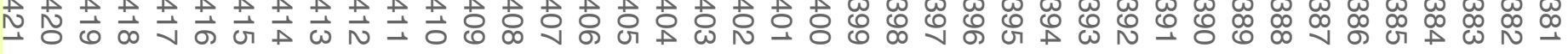




\section{FIGURE 1}

558 “Apple purée" experiment: mean $( \pm$ SEM) palatability score $(A)$, mean $( \pm$ SEM) amount 559 (kcal) (B) and mean ( \pm SEM) volume (L) (C) for both contrasting apple purées during the 560 expected satiation session and food intake sessions. The value for the least satiating apple 561 purée during the food intake session corresponds to the mean intakes during the food intake 562 sessions that involved this product.

563 Within-product differences: $P<0.001(* * *)$.

564 Within-session differences: $P<0.05(\#), P<0.01(\dagger), P<0.001(\dagger)$.

565

\section{FIGURE 2}

567 Dessert experiment: mean ( \pm SEM) palatability score (A), mean ( \pm SEM) amount (kcal) (B) 568 and mean $( \pm \mathrm{SEM})$ volume $(\mathrm{L})(\mathrm{C})$ for both contrasting desserts during the expected satiation 569 session and food intake sessions.

570 The value for the least satiating dessert during the food intake session corresponds to the 571 mean intakes during the food intake sessions that involved this product.

572 Within-product differences: $P<0.001(* * *)$.

573 Within-session differences: $P<0.001(\dagger)$.

\section{FIGURE 3}

576 Analysis of individual consumption ("apple purée" experiment). The actual intakes by 577 participants of individually selected apple purées plotted against the expected satiation of each 578 of the two products. $(\bullet)$ corresponds to the most satiating apple purée. $\left(^{\circ}\right)$ corresponds to the 579 least satiating apple purée (for each data point, the mean value of the two intake sessions for 
580 this product has been plotted). The solid line represents the area of no differences between

581 food intake and expected satiation. Hatched lines indicate the "consistency threshold" of \pm 33

$582 \mathrm{~g}(1 / 3$ of a standard portion; $18.7 \mathrm{kcal}$ for the "apple purée" experiment.

583

\section{FIGURE 4}

585 Analysis of individual consumption (“dessert” experiment). The actual intakes by participants 586 of individually selected desserts plotted against the expected satiation of each of the two 587 products. $(\bullet)$ corresponds to the most satiating dessert. $\left({ }^{\circ}\right)$ corresponds to the least satiating 588 dessert (for each data point, the mean value of the two intake sessions for this product has 589 been plotted). The solid line represents the area of no differences between food intake and 590 expected satiation. Hatched lines indicate the "consistency threshold" of $\pm 33 \mathrm{~g}(1 / 3$ of a 591 standard portion; $33.4 \mathrm{kcal}$ for the "dessert" experiment. 


\section{FIGURE 1}

595

A
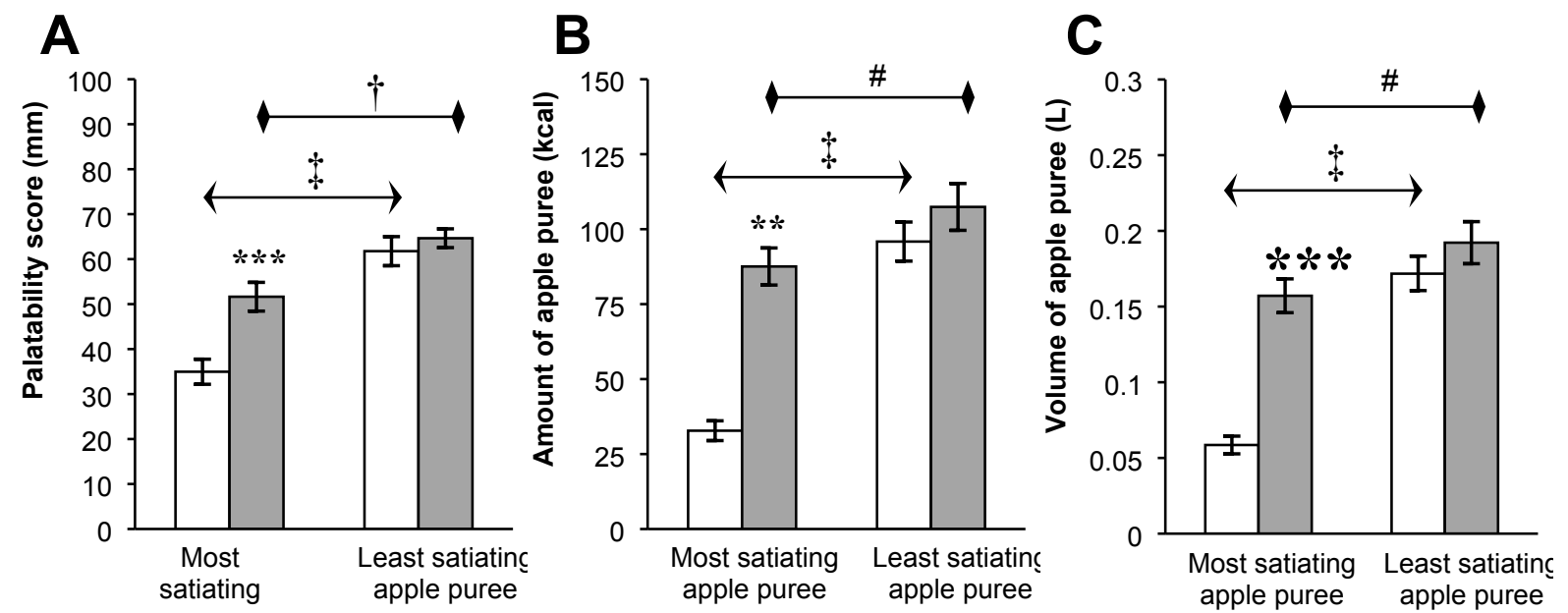

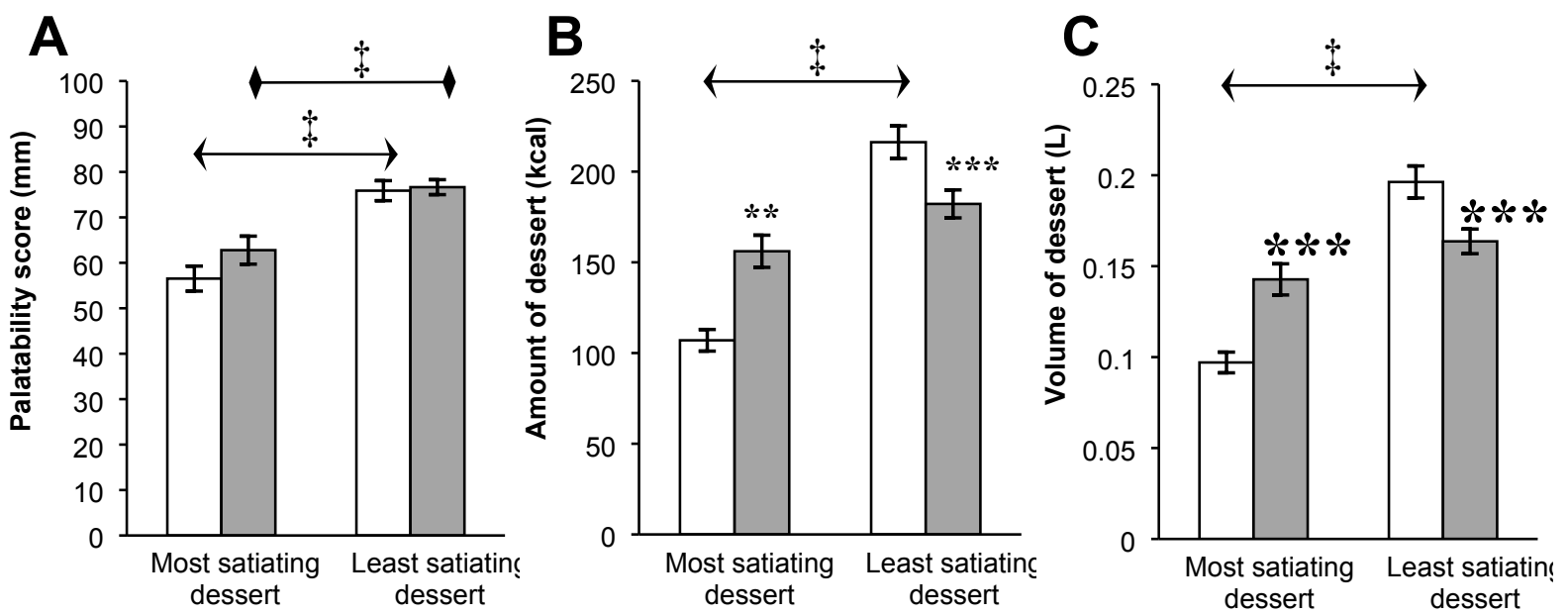
FIGURE 3

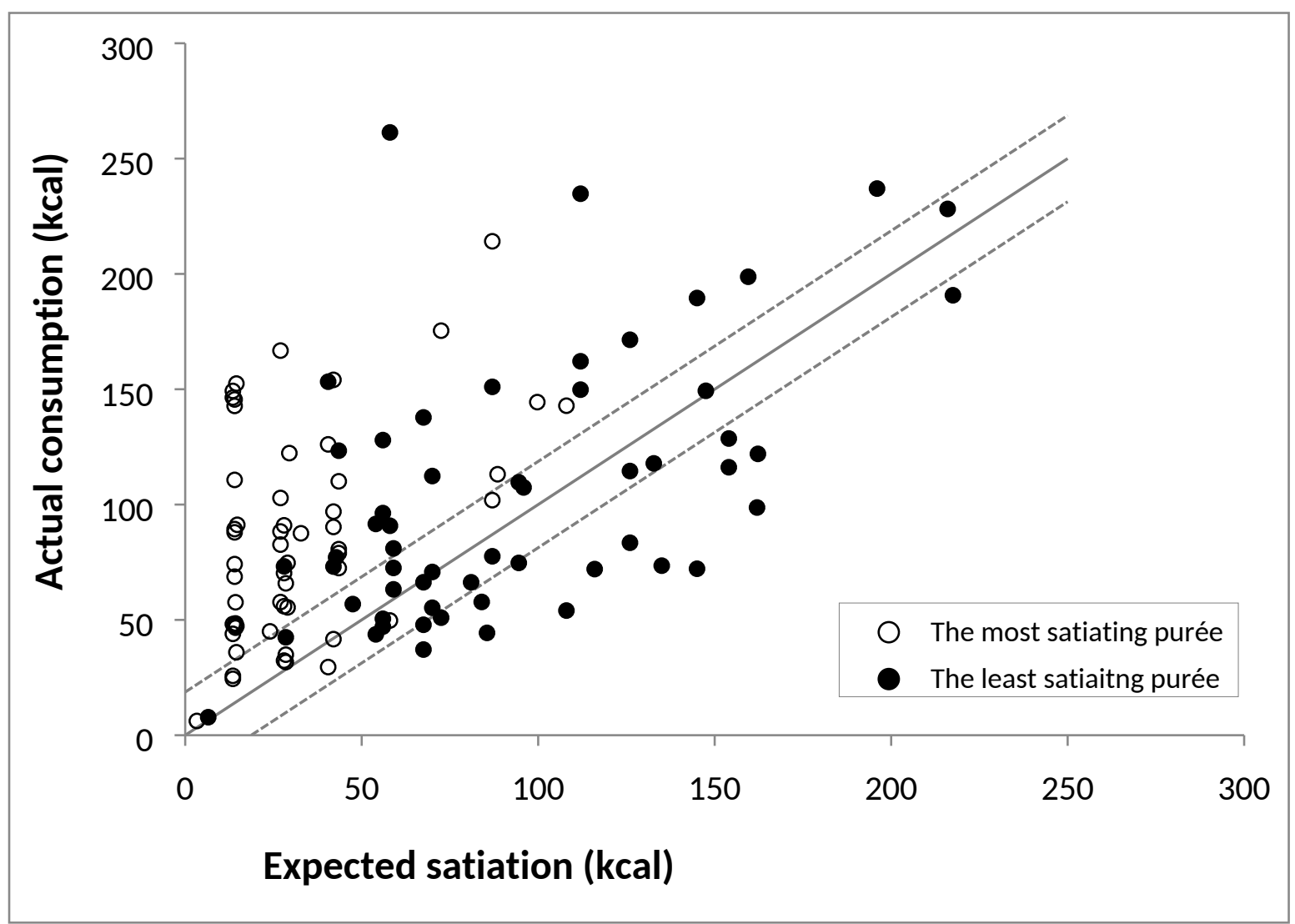


607 FIGURE 4

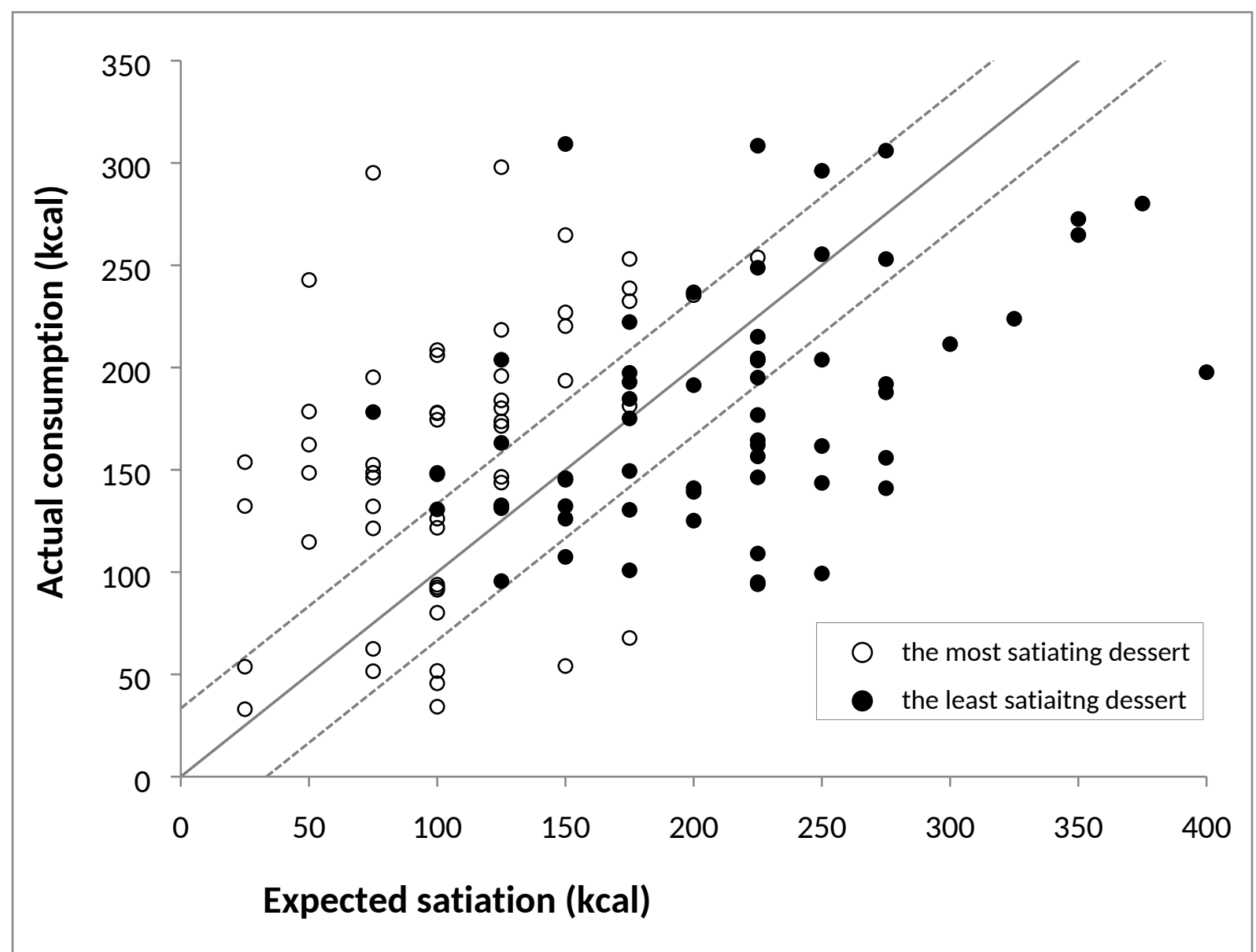

